

\section{La ficción y sus límites. Dos textos dramáticos sobre la rebelión tzeltal de 1712}

\section{Artículo de reflexión}

Recibido: 8 de mayo de 2020

Aprobado: 15 de julio de 2020

\author{
Vladimir González Roblero \\ Universidad de Ciencias y Artes de Chiapas, \\ México \\ vladimir.gonzalez@unicach.mx
}

Cómo citar este artículo: González Roblero, Vladimir (2021). La ficción y sus límites. Dos textos dramáticos sobre la rebelión tzeltal de 1712. Estudios Artísticos: revista de investigación creadora, 7(10) pp. 84-95.

DOI: https://doi.org/10.14483/25009311.17514

Este artículo es resultado del proyecto de investigación "Visiones del sur. Acercamiento a lenguajes poéticos de Chiapas", del Cuerpo Académico Estudios sobre Arte y Cultura de la Facultad de Artes de la Universidad de Ciencias y Artes de Chiapas.

\section{Resumen}

En el año 1712 ocurrió una de las rebeliones indígenas en la historia de Chiapas, en ese entonces provincia de la Capitanía General de Guatemala y actualmente estado del sur de México. Se trató del levantamiento de los indios tzeltales. Al respecto se han escrito crónicas, obras de teatro, novelas, además de artículos y libros historiográficos. Este ensayo analiza dos textos dramáticos y se pregunta sobre las representaciones del acontecimiento y su relación con los discursos historiográficos, con la finalidad de situar la frontera entre el arte y la ciencia como lugar de enunciación de dichas representaciones. Para tal fin, se recurre a la hermenéutica analógica, lo que permite la comparación de obras artísticas, en este caso literarias, con la historiografía. De este modo, entendemos que algunas obras reproducen los discursos historiográficos sin olvidar su naturaleza ficticia; mientras que otras ponderan la ficción sin olvidar sus articulaciones con lo real.

\section{Palabras clave}

Ficción; historiografía; rebeliones indígenas; representación

Fiction and its Limits. Two Dramatic Texts on the Tzeltal Rebellion of 1712

\footnotetext{
Abstract

In 1712, one of the indigenous rebellions in the history of Chiapas took place. At that time, the current southern state of Mexico was a province of the Captaincy General of Guatemala, and it saw the uprising of the Tzeltal Indians. Chronicles, plays, novels, as well as articles and history books have been written on the subject. This essay analyzes
} 
two stage plays and asks about the representations of the event and their relationship with historiographic discourses, with the aim of locating the border between art and science as the place of enunciation of said representations. For this purpose, analogical hermeneutics are used, which allows the comparison of artistic works, in this case literary creations, with historiography. In this way, we find that some works reproduce historiographic discourses without forgetting the fictitious nature of the latter; while others ponder fiction without forgetting their connections with reality.

\section{Keywords}

Fiction; historiography; indigenous rebellions; representation

\section{La fiction et ses limites. Deux textes dramatiques sur la rébellion de Tzeltal de 1712}

\section{Résumé}

En 1712, une des rébellions indigènes de l'histoire du Chiapas a eu lieu. À cette époque, I'actuel état méridional du Mexique était une province de la capitainerie générale du Guatemala, et il a vu le soulèvement des indiens Tzeltal. Des chroniques, des pièces de théâtre, des romans ainsi que des articles et des livres d'histoire ont été écrits sur le sujet. Cet essai analyse deux pièces de théâtre et interroge les représentations de l'événement et leur rapport aux discours historiographiques, dans le but de situer la frontière entre l'art et la science comme lieu d'énonciation desdites représentations. A cet effet, I'herméneutique analogique est utilisée, ce qui permet de comparer des œuvres artistiques, en l'occurrence des créations littéraires, avec l'historiographie. On constate ainsi que certaines œuvres reproduisent des discours historiographiques sans oublier le caractère fictif de ces derniers ; tandis que d'autres méditent sur la fiction sans oublier leurs articulations avec la réalité.

\section{Mots clés}

Fiction; historiographie ; rébellions indigènes ; représentation

\section{A ficção e seus limites. Dois textos dramáticos sobre a rebelião tzeltal de 1712}

\section{Resumo}

No ano de 1712 ocorreu uma das rebeliões indígenas na história de Chiapas, neste período província da Capitania Geral da Guatemala e atualmente estado do sul do México. Se tratou do levante dos índios tzeltales. A respeito, se escreveu crônicas, obras de teatro, novelas, além de artigos e livros historiográficos. Este ensaio analisa dois textos dramáticos e pergunta sobre as representações do acontecimento e sua relação com os discursos historiográficos, com a finalidade de situar uma fronteira entre a arte e a ciência como lugar de enunciação dessas representações. Para isso, se recorre à hermenêutica analógica, o que permite a comparação de obras artísticas, neste caso literárias, com a historiografia. Deste modo, entendemos que algumas obras reproduzem os discursos historiográficos sem esquecer sua natureza fictícia; enquanto que outras ponderam a ficção sem esquecer suas articulações com o real.

\section{Palavras chave}

Ficção; historiografia; rebeliões indígenas; representação

\section{Ruraspa mailla kaskakama kai iska kilkaskapi kawachiku kausariskakuna tzeltal kai watapi autun waranga iskun chunga. Chunga iskai kaura}

\section{Maillallachiska}

Kai watapi atun waranga iskun chunga, chunga iskun kaura nukanchipura runakuna munaskakuna kanchama llugsinga Chiapas sutimanda. Sug ruan paikuna kawadurkaska. Kunan punchapi kidami Mexico urapi. Kai pasariuramanda ruraskakuna Achka kilka ullachispa kauachispa iachachispa uturrimandata, Munanaku kai kilakakuna iuiachinga, tiami allí kilkaikuna, chasallata mana allilla iuiakunawa kilkaska pas mana ullariikuna tiangapa, paralaku allillata.

\section{Rimangapa Ministidukuna}

Ruraspa kawachii; kilkaita; tapuchii; nukanchita iuiachingapa; tukuikunata kausachii 


\section{Introducción}

Uno de los desplazamientos en torno a la idea de conocimiento ocurre en el uso de los conceptos aprehensión y representación. La epistemología considera que conocer significa aprehender la realidad, es decir, hacerse un cuadro completo de las cualidades del objeto a través de la experiencia (Villoro, 1996). Además de lo anterior, el conocimiento también es representación, es decir, el estudio de las observaciones de los objetos (Mendiola, 2006). Este viraje hacia la representación es lo que permite identificar una frontera entre la ciencia y el arte, entre la realidad y la ficción. Dicha frontera epistemológica se reflexiona aquí desde tres supuestos sobre la representación y se ejemplifica con textos dramáticos que indican los límites de la historia y la literatura. Al abordar el problema de la representación del pasado histórico, Paul Ricoeur (2006) dice que este podría pensarse como lo Mismo desde que identificamos al relato como su sustituto. Al cuestionar este supuesto por considerarlo inviable, decide abordarlo desde lo Otro. Aquí el historiador se distancia del pasado y el relato se diferencia del haber-sido. Pero este tampoco le satisface porque niega toda relación de la narración con el pasado real. Finalmente llega a la analogía como la figura que establece este vínculo sin que sea idéntico o distinto. De este modo niega la representación, pues esta supone la reduplicación del pasado, tarea imposible debido a que se accede a él solo a través de huellas. La palabra que designa mejor esta relación es representancia. Ella cancela la vieja pretensión historiográfica de narrar el pasado tal como para presentarlo como si. Esto solo es posible a través del relato. Para lo anterior echa mano de la ficción, de figuras tropológicas: metáfora, metonimia, sinécdoque e ironía. Aunque se corre el riesgo de borrar las fronteras entre la historia y la ficción, esto no sucede. El relato historiográfico pondera las huellas o fuentes, garantes del pasado, y se explica bajo los regímenes de verdad científicos.

Este acercamiento se amplía con las propuestas de Michel Foucault (2008), quien sostiene que a lo largo del tiempo el conocimiento se ha construido a partir de continuidades y rupturas en las formas de representar las cosas. Estas se rastrean desde las semejanzas y diferencias, es decir, lo Mismo y lo Otro. Los límites de la representación entonces se conocen en relación a lo representado en cualquiera de sus formas. Así pues, por ejemplo, la emulación como una forma de similitud marca unos límites de representación, mientras que la analogía ofrece un número infinito. De este modo, dice, conocer (representar) será interpretar. Finalmente, estas consideraciones se complementan con la hermenéutica analógica. Mauricio Beuchot (2008) busca hacer una síntesis de las formas de interpretación que han predominado, a saber: la univocidad y la equivocidad. Considera que la analogía es punto medio entre éstas dos. Ella alberga la metonimia y la metáfora. Una interpretación analógica permitirá una lectura que no pretende las interpretaciones literales y que limite la infinitud.

Estas consideraciones orientan los análisis de dos textos dramáticos sobre la rebelión tzeltal de 1712 ocurrida en Chiapas, México. Se trata de Los agravios de su ilustrísima, guion para teatro de Alfredo Espinosa; y Los embustes de San Tanás, guion para cine de Antonio Coello. Como veremos, las dos representaciones de la rebelión se ubican en los extremos, queriéndose y negándose como sucedáneos del pasado. En términos generales, considero tres aspectos para identificar la relación que existe entre estas ficciones y la realidad del pasado. Primero: que ambos se refieren a un pasado reconocible; segundo: que ese pasado se ha prefigurado como un modelo capaz de ser representado, y tercero: la representación, a pesar de sus extremos, implican discursivamente a los lectores y a sus posibles espectadores. Con este último aspecto asistimos a una pretensión: despojar al arte y la literatura de la supuesta incapacidad de actuar en la realidad.

\section{Relatos de la rebelión}

En noviembre de 1712 la entonces conocida como Provincia de los Zendales fue el espacio donde se desarrolló una de las primeras rebeliones indígenas de la América Central. Su epicentro fue el pueblo de Cancuc y se extendió a otras provincias como Las Coronas y Chinampas, además de la Guardianía de Huitiupán (Viqueira, 2002, p. 103). No era la primera vez que la Virgen se aparecía. En Zinacantán, en 1708 , un ermitaño invitaba a rendir culto a la Virgen desde un hueco del tronco de un árbol. El ermitaño fue apresado y examinado. Tiempo 
después, en 1710, ya en libertad, regresó a predicar, ahora en una capilla que había sido construida para el culto. La capilla fue quemada por los frailes y el ermitaño enviado a Ciudad Real (Reifler, 1989, pp. 112-114).

Posteriormente la Virgen volvió a aparecerse en Santa Martha a una indígena de nombre Dominica López. Le construyeron una capilla y rindieron culto. Al enterarse los frailes, Dominica y otros fueron hechos prisioneros. Mientras era juzgada en Ciudad Real se supo la noticia de la aparición de la virgen en Cancuc. (Reifler, 1989, p. 120).

En sentido braudeliano, el acontecimiento de la rebelión se ubica cuando una indígena de nombre María López creyó ver y escuchar a la Virgen, quien le dijo que debía rebelarse contra las autoridades españolas, civiles y eclesiásticas. La Virgen le pidió a la india tzeltal que construyera en Cancuc una ermita. A partir de entonces María de la Candelaria, como así se había renombrado, junto con cinco mayordomos de la ermita, arengaron a los tzeltales prometiéndoles liberarse del cautiverio español, pues había llegado la hora de dejar de pagar tributos y desconocer al rey, al obispo, al alcalde mayor (Viqueira, 2002, p.125).

Las promesas se extendieron en las provincias antes mencionadas; incluso se llegó a temer que la rebelión alcanzara Ciudad Real, hoy San Cristóbal de Las Casas. Al final fue sofocada. Las tropas españolas avanzaron con la Virgen de la Caridad por delante, a quien habían nombrado generala. Lograron derrotar a los sublevados. Por este hecho a la rebelión también se le conoce como la guerra de las dos vírgenes. Los mayordomos fueron hechos prisioneros y María de la Candelaria huyó. Tiempo después se supo que había fallecido en trabajo de parto, en la montaña (Orozco y Jiménez, 1999, pp. 135,138$)$.

Las causas no se hallan solo en este tiempo corto. Otras temporalidades históricas nos ayudan a entenderla. En primer lugar, y aquí sigo a Viqueira, en la alcaldía mayor de Chiapas, como la Colonia misma, el orden social se construyó a partir de la idea de castas. "La oposición entre los españoles... y los indios tomó tintes necesariamente extremos dada la casi ausencia total de otras castas que ocuparan posiciones sociales intermedias..."
(Viqueira, 2002, p. 106). Junto a esta circunstancia, los conflictos étnicos siempre estuvieron a flor de piel, ocasionados no solamente por las condiciones económica y de pobreza, sino también por las diferentes concepciones de mundo.

Además de los mundos encontrados, los conflictos también se presentaron entre los mismos españoles. La evangelización no estaba resultando como se esperaba y este fracaso se les adjudicaba a las órdenes dominicas. Lo anterior ocasionó algunos desacuerdos al interior de la Iglesia. Entre ellas, dice Viqueira, el obispo de Chiapas y el Soconusco, Marcos Bravo de la Serna "propuso al Consejo de Indias secularizar las 7 doctrinas dominicas de LoS Zendales, lo que le valió las iras de los religiosos" (Viqueira 2002, p. 117). Junto a lo anterior también hubo disputas por la Alcaldía Mayor. El alcalde entró en controversia con los hombres acaudalados, quienes le disputaban el control económico de la región, a tal grado que, por sus influencias, hizo que alguno de ellos huyera a Tabasco, desde donde logró denunciar los "ilegales manejos del alcalde mayor" (Viqueira, 2002, p. 122).

En este marco se desarrolló la rebelión. La historia ha sido recuperada por cronistas, historiadores y escritores de ficción. El primer trabajo narrativo fue el de Fray Francisco Ximénez. Como otros cronistas de la Conquista y Colonia, Ximénez desembarcó en estas tierras alrededor de 1688. Acompañaba a Jacinto de Barrios Leal para entonces nuevo gobernador y capitán general de Guatemala (Ximénez, 1997). Aprendió la lengua quiché y se convirtió en cronista. Escribió su Historia de la provincia de San Vicente de Chiapa y Guatemala, donde relató la rebelión de Cancuc. El texto de Ximénez, los testimonios que recoge, han servido de base para otros más. Hasta el siglo XIX otro cronista se ocupó del acontecimiento. Lo hizo Vicente Pineda (1986) en su Historia de las sublevaciones indígenas en Chiapas en 1888. Discurso propio de su tiempo, Pineda mira también el choque de la civilización y la barbarie.

Posteriormente, Victoria Reifler Bricker en su monumental El cristo indígena, el rey nativo, se ocupó del acontecimiento. Su tratamiento está enmarcado en el análisis de las rebeliones indígenas en la zona maya, historias que alimentan las ritualidades indígenas. Prudencio Moscoso Pastrana, por su 


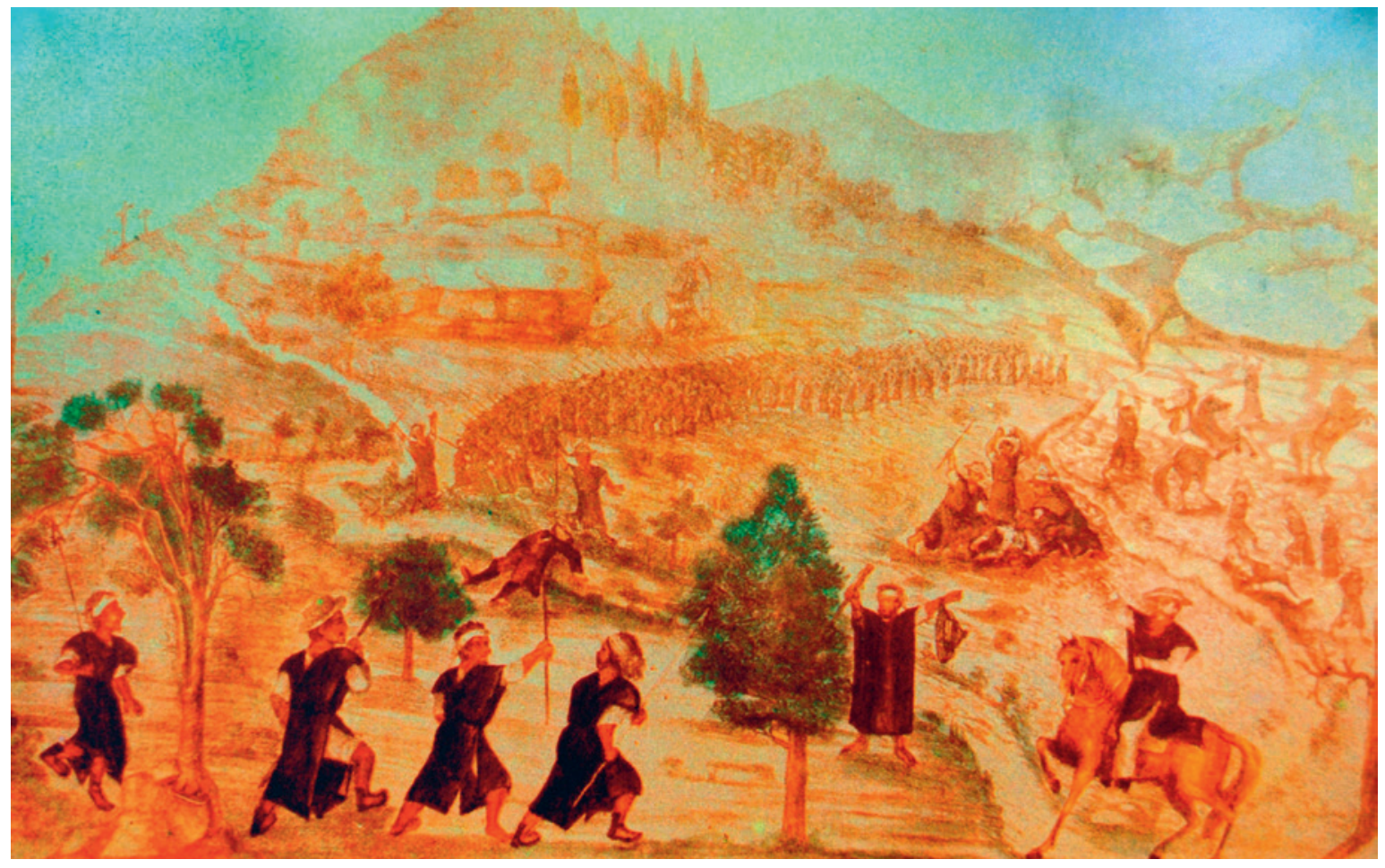

José Pedro Martínez, 1869, de la serie Guerra de castas chiapaneca. Otra de las rebeliones indígenas de Chiapas que ha inspirado la creación artística es la rebelión tzotzil de 1869. En el siglo XIX se escribió una novela, Florinda, de Flavio Paniagua, y se produjo una serie de litografías de José Pedro Martínez. Fotografía: Cortesía de Mario Nandayapa.

parte, en su Rebeliones indígenas en los Altos de Chiapas (1992) también dedica páginas a la rebelión. Pero quizá los trabajos que se han detenido más en ella son los de Juan Pedro Viqueira. Al menos tres se pueden considerar en una bibliografía básica. Se trata de Indios rebeldes e idólatras (1997); "Las causas de una rebelión india: Chiapas, 1712", aparecido en Chiapas, los rumbos de otra historia, que coordinó junto a Mario Humberto Ruz y "Resistencias indias a la rebelión tzeltal de 1712, Chipas" (2012). En todos ellos Viqueira quiere apartarse del relato que se ha impuesto sobre la rebelión, sobre todo aquel que busca en la historia acontecimiento su hilo conductor. Más allá de esto se pregunta por las causas, las consecuencias y los actores ya no como esa historia manida de oprimidos y opresores, sino también de alianzas estratégicas.

Finalmente, Jan de Vos publicó en 2011 un libro excepcional. Se trata de La guerra de las dos vírgenes. La rebelión de Los Zendales (Chiapas, 1712) documentada, recordada, recreada. Su particularidad e importancia radica en que publica varios documentos sobre la rebelión, testimonios orales recogidos por los antropólogos siglos después, en los que María de la Candelaria es opacada por un héroe mítico, Jwan Lopes, y varios fragmentos de obras de ficción.

Pero no solo la crónica y la historia se han ocupado de los sucesos de Cancuc. Otros ejercicios narrativos cuyas pretensiones referenciales escapan a una idea de verdad articulada a la demostración empírica, han abordado el acontecimiento. Me refiero a los escritores de ficción. Con sus textos, el gran enunciado, la rebelión, se complementa. Algunas novelas, obras de teatro y cine se han escrito al respecto. En el siglo XIX vio la luz la novela histórica Don Juan Núñez García del guatemalteco Agustín Mencos Franco. El nombre de la novela se debe a quien ha sido considerado uno de los líderes, Juan García. En ese mismo siglo se publicó el guion teatral María de la Candelaria: An historic drama from American Aboriginal Life, de Daniel Brinton (1897). La pieza contiene una 
introducción donde se aborda la historia del levantamiento.

Ya en el siglo XX Heberto Morales Constantino (2010) escribe Jovel, serenata a la gente menuda. Es una novela que rastrea los orígenes españoles de San Cristóbal de Las Casas. En ella permea la idea de mestizaje sobre la que se fundó la ciudad. La historia es la errancia: el andar de españoles hasta asentarse en el valle de Jovel, sus hibridaciones y propósitos. La novela concluye precisamente con la rebelión tzeltal. Aquí el mestizaje aparece cuando algunos ladinos se niegan a participar contra los sublevados.

Otro texto de Juan Pedro Viqueira (1996), pero este a medio caballo entre la historia y la ficción, es María de la Candelaria, india natural de Cancuc. Es un trabajo que plantea la tesis historiográfica, su tesis, de que la sublevación fue planeada conscientemente por los indígenas. El genio novelesco y algunos elementos ficticios la ubican como una pieza literaria y no historiográfica.

El escritor guatemalteco Ronald Flores publicó en 2008 la novela histórica La rebelión de los zendales. La novela se basa en la crónica de fray Francisco Ximénez. Con ella busca situar la rebelión en el contexto centroamericano de la Colonia.

Finalmente, dos guiones, uno para teatro y otro para cine. El primero se llama Los agravios de su ilustrísima, de Alfredo Palacios Espinosa; el segundo Los embustes de San Tanás de Antonio Coello. En ellos me detendré a continuación.

\section{Los agravios de su ilustrísima}

En 1993 se estrenó Los agravios de su ilustrísima en el Teatro de la Ciudad Emilio Rabasa, en Tuxtla Gutiérrez. La obra es parte de la producción literaria y escénica de Alfredo Palacios Espinosa, escritor chiapaneco nacido en La Concordia. Varias de sus novelas, cuentos, anecdotarios y piezas dramáticas, hacen una lectura comprometida de la historia de Chiapas. Los confines de la utopía, novela publicada en 1992, aborda la rebelión tzotzil de 1869 y la intervención chamula en el contexto de la Revolución mexicana. Al menos la primera parte de esta novela se puede calificar como una novela histórica de tesis. En ella sostiene y defiende la idea de que la rebelión fue causada por los ladinos y reivindica la histórica resistencia indígena. Otros textos suyos abordan la historia local, como Los malos presagios, El tribuno y el usurpador o El heredero y el miedo, por citar algunas.

En Los agravios de su ilustrísima, publicada como guion en 1994, Palacios vuelve a presentar una tesis: la rebelión de 1712 se entiende como resultado de luchas intestinas de las élites locales. Las pugnas por el poder eclesiástico y civil en la entonces Alcaldía Mayor de Chiapa, así como los cobros excesivos de impuestos y la pobreza de los indígenas, los orillan a sublevarse. La historia se plantea, según la cuarta de forros, desde la "óptica de los vencidos". Uno de sus paratextos, los antecedentes, dice: “Es pues, esta obra, un recuento dramático de una infamia más, cometida contra los naturales de América."

El texto dramático propone una representación que emerge de lo Mismo. No en el sentido de la reduplicación del pasado como haber-sido sino del pasado como relato. Sigue líneas de argumentación de la historiografía. Este hecho lo encadena a un pasado que para 1994 ya había sido construido por los historiadores. Al menos las crónicas de Francisco Ximénez, Vicente Pineda y Prudencio Moscoso refieren algunas de ellas; también lo hacen el texto de Victoria Reifler y un capítulo de Juan Pedro Viqueira. Estos mismos argumentos son los que ha ampliado el mismo Viqueira en trabajos posteriores a 1994 y otros investigadores sobre el tema.

Tres son las líneas de argumentación en Los agravios de su ilustrísima que permiten sostener la historia como lo Mismo. En primer lugar, el conflicto eclesiástico. Este se presenta a través de los señalamientos del obispo Juan Bautista Álvarez de Toledo hacia los frailes dominicos. En la obra de teatro los acusa de descuidar el proceso de evangelización, lo que ha dado como resultado que los indios sean propensos a la idolatría. Detrás de esta acusación, sugiere la historia ficcionalizada, se hallaba la ambición del obispo por controlar los impuestos y otros cobros a la población indígena.

La segunda línea de argumentación es el conflicto entre las élites civiles. La obra de teatro supone 


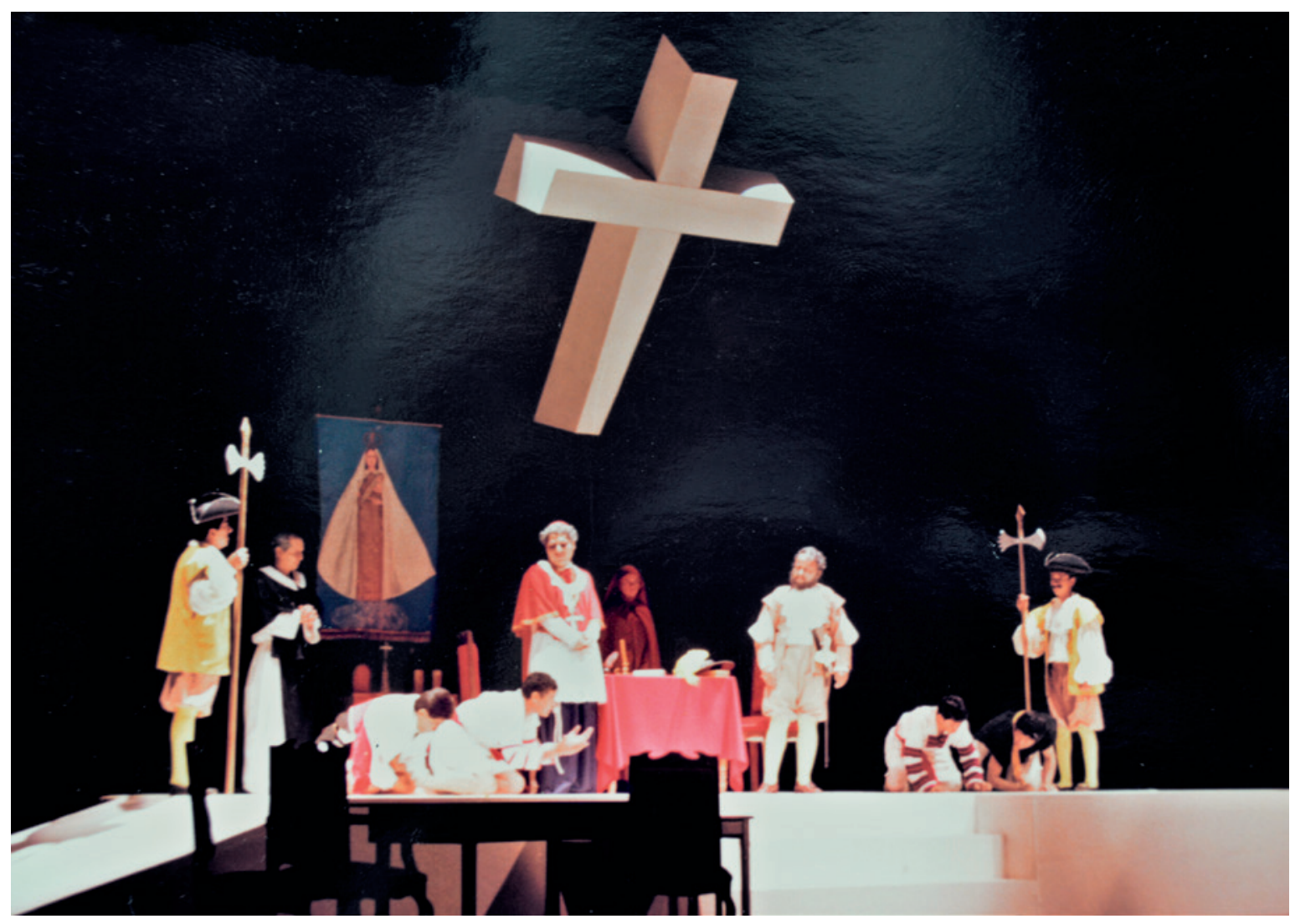

Imagen 2. La obra de teatro Los agravios de su ilustrísima se estrenó en junio de 1992 en el Teatro de la Ciudad en Tuxtla Gutiérrez, Chiapas. Fotografía: Cortesía de Héctor Cortés Mandujano.

que el alcalde mayor, Martín González de Vergara, tiene deudas económicas con españoles peninsulares y criollos, comerciantes ellos, a los que llama fiadores. Son quienes cobran al alcalde dinero que le han prestado y, además, piden participar en el comercio del maíz, frijol y licor. Es decir, buscan el control de la alcaldía y sitúan en medio de ellos a los indios.

La tercera línea son las condiciones de pobreza que padecen los indígenas. Estas se acrecientan por dos circunstancias. La primera, ya manida, se refiere a la ambición mezquina del obispo Juan Bautista Álvarez de Toledo. El obispo incrementa el cobro del tributo al Rey dejándolos en la pobreza, vendiéndoles "a precio de carestía"; en esas fechas, además, se registró una plaga que terminó con los sembradíos, habiendo también enfermedades. Ante estas circunstancias de explotación los indios miraron en lo dicho por la virgen la oportunidad para liberarse.
Una última línea, no propiamente de argumentación, identifica al relato dramático con el historiográfico. Se trata de la guerra de las vírgenes. La Virgen María, la misma que le ha hablado a María de la Candelaria, es la protectora de los indios. Frente a ella los españoles, sus autoridades eclesiásticas y el ejército, colocan a la Virgen de la Caridad. El obispo la nombra Generala y va en la avanzada del ejército. Es su protectora.

Como se ve el relato literario es cercano al relato historiográfico. Volvamos a Ricoeur. Al preguntarse por la realidad del pasado histórico, sostiene que una de las maneras de abordarlo es como lo hizo cierta corriente historiográfica identificada con Ranke y con el mismo Collingwood. La enuncia a partir de pensar el pasado tal como ocurrió. Esta condición se da en el relato. Aquí se impone la figura de lo Mismo. Es interesante hacer notar que en el caso que me ocupa el referente de lo Mismo es el relato historiográfico y no el pasado como 


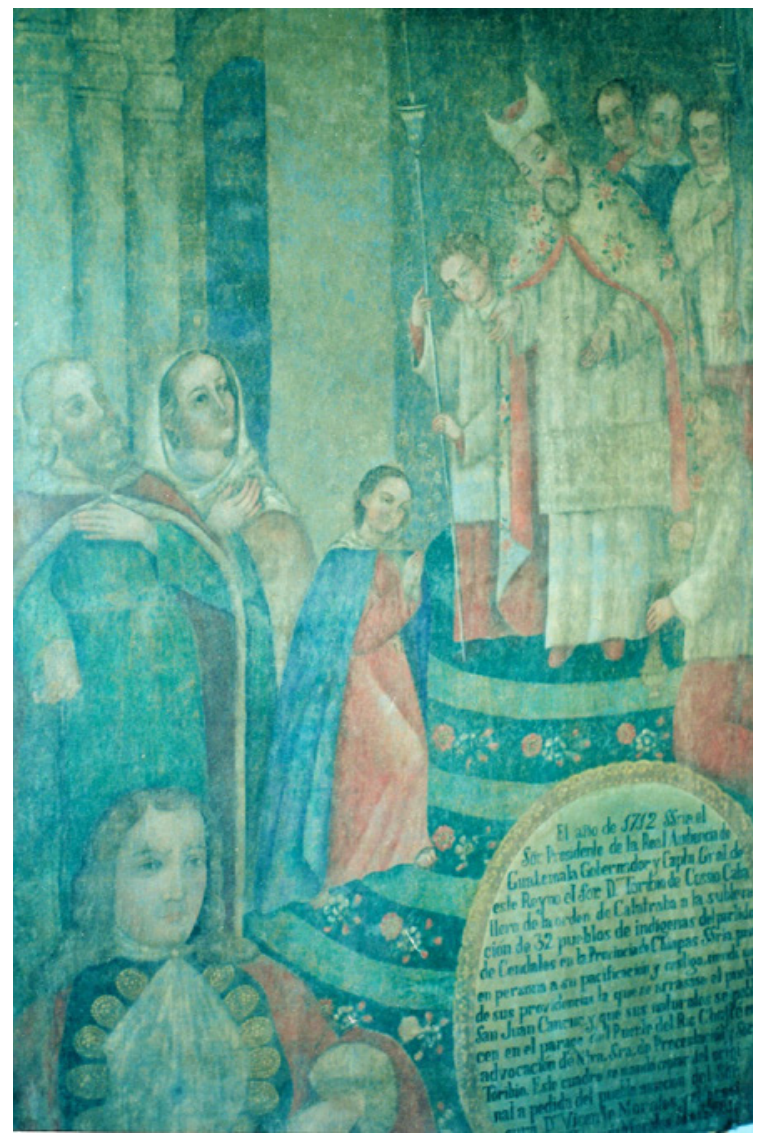

haber-sido. Cuando Platón se hacía la pregunta por el arte, decía que este es apariencia de la forma. Es decir, el artista que esculpía o pintaba, por ejemplo, una mesa, imitaba algo que ya había sido creado, en este caso, por un carpintero quien, a su vez, imitaba una creación divina. De este modo es posible pensar el relato dramático como apariencia del relato historiográfico. El hecho de haber seguido las líneas de argumentación, posibles comprensiones del hecho histórico que han aventurado los cronistas e historiadores, encadena a la obra de teatro con un pasado que ya ha sido creado.

La diferencia entre estos dos relatos son los criterios de verdad. El historiográfico se circunscribe a la verdad científica, es decir, la comprobable con evidencias empíricas. El documento se erige aquí como huella del pasado. El literario o dramático carece de esta pretensión, no echa de menos a los documentos y se ciñe a lo posible. Su verdad se efectúa en la experiencia estética. Cosa difícil
Imagen 3. Inmediatamente después de la rebelión tzeltal, el presidente de la Audiencia de Guatemala, Toribio de Cosío, mandó a pintar un lienzo de la Presentación de la Virgen en el Templo, con la finalidad de que los indios sublevados no olvidaran su derrota. En Cancuc se conoce como el Lienzo de la Virgen. Fotografía: Cortesía de Juan Pedro Viqueira.

en el texto dramático pues su naturaleza es la representación.

Ahora bien, una duda. ¿Consultó Alfredo Palacios documentos primarios? Su respuesta requiere un trabajo minucioso que escapa a la brevedad de este texto. Pensemos en lo posible. La crónica de Ximénez, pero también algunos documentos publicados en el libro de Orozco y Berra estaban disponibles. De haberlo hecho entonces podríamos aventurar esto: lo Mismo no es en función al relato historiográfico, sino al relato dramático como pasado.

\section{Los embustes de San Tanás}

Casi doce años después de Los agravios de su ilustrísima, en 2005, otro texto dramático abordó los acontecimientos de 1712. Se trata del guion cinematográfico Los embustes de San Tanás de Antonio Coello. Con el subtítulo “Tragicomedia de una rebelión indígena", refresca la grave mirada 
de Los agravios. Su autor es un cineasta que ha dirigido los cortometrajes El rey de Zinacantán con el que participó en el segundo Festival de Cine de Morelia, y Chimbumbe, con el que ganó en 2008 el premio India Catalina otorgado al mejor cortometraje de ficción en el Festival Internacional de Cine de Cartagena de Indias, Colombia. La propuesta estética de Coello se sustenta en la recuperación de la memoria y las historias de pueblos originarios o minorías.

Dicha frescura lo ubica en el extremo de lo Otro. Esto quiere decir que su relación con el pasado, en tanto haber-sido y como relato, es diferente. Se quiere una versión libre de lo acontecido en Cancuc. La diferencia está en el tratamiento. La historia se plantea como tragicómica. En ella las ocasiones festivas se desarrollan con la intervención de Jwan Lopes, una especie de héroe cuyas acciones y gestos rayan en el anacronismo y de quien su final es trágico. Este personaje marca la diferencia con el pasado. Su aparición no es relatada en la historia sino en la memoria. Antonio Coello lo recupera de relatos orales, posiblemente tomados de los registros antropológicos al respecto y de su propio trabajo de investigación de campo.

El guion cinematográfico guarda una relación endeble con el relato histórico. Apenas se puede rastrear a través de la historia de María de la Candelaria. La heroína de otros relatos aquí es un personaje secundario. Esta trama es básicamente la misma: la joven a quien la Virgen le habla, le pide construir una ermita y la alienta a rebelarse contra la opresión indígena. Su derrota ocurre frente a la Virgen de la Caridad. La novedad -mejor otredadestá en la recurrencia a la memoria y a la comedia. Con ellas se efectúa una de las posibilidades infinitas de la representación.

Jwan Lopes es un personaje de la memoria colectiva tzeltal. Aquí su tratamiento es como héroe. Su construcción así lo sugiere. Las características del personaje heroico aluden a su origen misterioso, desenfreno juvenil, espíritu aventurero, viajante al origen, encuentros con una diosa y retornos triunfales (Siemens, 1997, p. 13). Además de estos, Raglan (Siemens, 1997, p. 14) agrega: nace de una virgen, su padre es un rey, las circunstancias de su concepción no son claras, no se conoce su infancia, pierde el favor de los dioses y muere sin recibir sepultura.

Estas características definen al héroe clásico. Muchas de ellas coinciden con Jwan Lopes. El personaje es concebido extrañamente por el Señor de la Cueva y nace siendo joven; comienza sus aventuras en el pueblo tzeltal, donde se define su estilo cómico; se enamora de María de la Candelaria con quien mantiene relaciones sexuales; tiene poderes que lo hacen casi inmortal; después de enamorar a María de la Candelaria los mayordomos desconfían de él; lo matan cuando Jwan les rebela el secreto de cómo hacerlo, y es tirado a un barranco de donde ya no puede salir. Esta historia configura su inmortalidad y lo sitúa en la memoria tzeltal. Algunos dicen que incluso ya se reclutó en el Ejército Zapatista de Liberación Nacional. El vínculo con lo ocurrido en 1712 es a través de la memoria, pues sus acciones heroicas, según la oralidad, suceden cuando en Cancuc había guerra (De Vos, 2011, pp. 249-269).

La historia tragicómica desacraliza las lecturas comprometidas de las ficciones históricas y parodia las historiográficas. La sensualidad de María de la Candelaria es una de sus estrategias, así como la concupiscencia del obispo Juan Bautista, quien "peca" con la madre superiora y enferma de sífilis. Lo cómico, dice Adolfo Sánchez Vázquez (2005, p. 233), es la contradicción: cuando los fenómenos suceden en contextos fuera de lo esperado. Es también una forma de crítica. Sostiene: "Mientras el orden establecido se ampara en la seriedad y solemnidad para legitimarse, la risa mina sus cimientos". Los relatos historiográficos y literarios sobre la rebelión se han construido bajo el signo de lo Mismo. Este guion cinematográfico se sitúa en lo Otro. La diferenciación deviene crítica a la forma en que la historia ha sido contada. El humor y la parodia, como formas cómicas, distancian al relato del pasado factual y del ficcionalizado. Sin embargo, no pretende distanciar a los lectores. Sino al contrario, la crítica despierta simpatías.

Otra característica de Los embustes es el entrecruzamiento de la memoria y la historia. Roger Chartier (2007) sostiene que la memoria es una de las modalidades que nos relacionan con el pasado, además de la historia y la ficción. Estos entrecruzamientos suceden de la mano de Jwan Lopes y 
María de la Candelaria. La existencia del primero, en tanto memoria, se sujeta a la función fiduciaria del testimonio; la segunda a la función indiciaria del documento. Imposible dudar de María de la Candelaria como posible reconocer el pasado en Jwan Lopes. Aunque Jan de Vos duda de mezclar la historia y la memoria, "dos maneras de recordar el pasado" (De Vos, 2005, pp. 17-18), es posible reconocer aquí una frontera. Los regímenes de verdad a los que pertenecen, a saber, lo fiduciario y lo indiciario, se imbrican en la ficción. Es la ficción el espacio común.

Entonces lo Otro es posible a través de Jwan Lopes, lo tragicómico y la ficción como frontera. La representación del pasado en Los embustes es completamente metafórica. Su relato no se identifica con el pasado creado, aunque algo de este asoma. Me atengo aquí a la idea de Michel de Certeau (2006). En La escritura de la historia, al abordar la operación historiográfica, considera que el pasado es distinto a su narración. El énfasis se articula con el discurso como diferente al relato. Y el discurso está condicionado por el lugar de enunciación del autor del relato. La diferenciación del pasado entonces ubica al guion cinematográfico en el plano de lo discursivo. De este modo comprendemos por qué la historia narrada en la ficción no es el pasado. La manera en que se nos presenta, sin embargo, produce sentido en el lector. ¿Por qué se ha escogido una versión tragicómica? Es un señalamiento, quizá, a los discursos historiográficos y literarios hegemónicos.

\section{Conclusión}

Las representaciones del pasado en Los agravios de su ilustrísima y en Los embustes de San Tanás se hallan en los opuestos. En estas condiciones es posible recordar la analogía como la sugiere Mauricio Beuchot (2013). Si pensamos, como lo hace Foucault (2008), que la semejanza y la diferencia han sido importantes para la construcción del saber en Occidente, y que estas han orientado la representación de las cosas, podemos identificar los debates hermenéuticos de la univocidad y la equivocidad. Es decir, la representación del pasado implica su interpretación.
Las representaciones en Los agravios y Los embustes, como lo Mismo y lo Otro, equivalen a la metonimia y a la metáfora como figuras distantes. La primera por su sentido literal y la segunda por alegórica. Beuchot considera que una forma de acercarlas es a través de la analogía. Su propuesta parte de un matiz a la idea de analogía de Ricoeur. En principio Ricoeur (2006, pp. 854-863) considera que la analogía es lo que une lo Mismo a lo Otro y que ella hace efectivo el vínculo de la narración con el haber-sido. A esta relación la llama representancia y opera a través del relato. En este el pasado ya no se presenta tal como ocurrió sino como si. Considera que la metáfora es la forma de la analogía. El señalamiento de Beuchot $(2013$, p. 26) es que la metáfora es la más cercana a la equivocidad. Para él la hermenéutica analógica es intermedia entre lo unívoco y lo equívoco porque evita reducirse a la literalidad e impide dispersarse en la alegoría. En este sentido la metonimia y la metáfora son aspectos de la analogía.

Desde esta perspectiva es posible pensar que Los agravios y Los embustes son interpretaciones analógicas del pasado. Si el primero se identifica con lo Mismo, no deja de contener diferencias; si el segundo se identifica con lo Otro, no deja de contener semejanzas. Los agravios es una obra cercana a las líneas de argumentación de los relatos historiográficos, pero no por eso es distinta a la ficción, con diálogos y escenas fingidas. Los embustes, se diferencia de los relatos historiográficos, pero no por eso olvida la estructura primigenia de la narración histórica de la rebelión, lo que recuerda la historicidad de lo ahí narrado.

Además de esta visión en conjunto de los textos dramáticos, podemos pensar en otra desdiferenciación. ¿Dónde dialogan estas obras de ficción entre sí y con los relatos historiográficos? Lo hacen en el nivel del discurso. Uno de los aspectos de la frontera como lugar común entre la historia y la literatura es su capacidad para ampliar o complementar las formas de conocer el mundo. Sobre la rebelión tzeltal de 1712 se han escrito estos y otros textos, con pretensiones distintas, criterios diferentes, aspiraciones otras. Sin embargo, cada uno de ellos, como géneros discursivos, construyen el enunciado de lo que han llamado la guerra de las dos vírgenes. 


\section{Referencias}

Beuchot, M. (2008). Perfiles esenciales de la hermenéutica, México: Fondo de Cultura Económica.

(2013), “Una hermenéutica analógica para la literatura", en Connotas. Revista de crítica y teorias literarias, número 13, pp. 11-23.

Brinton, D. (1897). "María Candelaria", an historic drama from american aboriginal life, David Mickey(Edit.), Philadelphia

Coello, A. (2005). Los embustes de San Tanás, Chiapas: Coneculta.

Chartier, R. (2007). La historia o la lectura del tiempo, España: Gedisa.

De Certeau, M. (2006). La escritura de la historia, México: Universidad Iberoamericana.

De Vos, J. (2005). "Prólogo. La fascinación por un héroe tzeltal", en Antonio Coello, Los embustes de San Tanás, (pp. 13-18), Chiapas: Coneculta.

. (2011). La guerra de las dos vírgenes. La rebelión de Los Zendales (Chiapas, 1712) documentada, recordada, recreada,: México: Ciesas, Unam. Unicach.

Ferrera-Balanquet, R. M. (2018). Imaginarios y estrategias decoloniales. Estudios Artísticos, 4(4), 42-61. https://doi. org/10.14483/25009311.12932

Foucault, M. (2008). Las palabras y las cosas. Una arqueología de las ciencias humanas, México: Siglo XXI.

Mendiola, A. (2006). "Las representaciones como temas de estudio de la historia. Una aproximación desde Lous Marin", en Valentina Torres Septién, Producciones de sentido, 2. Algunos conceptos de la historia cultural, (pp. 343-355), México: Universidad Iberoamericana.

Morales Constantino, H. (2010). Jovel, serenata a la gente menuda, México: Coneculta.
Moscoso Pastrana, P. (1992). Rebeliones indígenas en Los Altos de Chiapas, México: UNAM.

Orozco y Jiménez, (1999). Documentos inéditos de la historia de la Iglesia en Chiapas, tomo II, Chiapas: Coneculta.

Palacios Espinosa, A. (1994). Los agravios de su ilustrísima. Memorial dramático en tres actos, México: Instituto nacional indigenista

Pineda, V. (1986). Sublevaciones indígenas en Chiapas. Gramática y diccionario tzeltal, México: INI.

Reifler Bricker, V. (1989). El cristo indígena, el rey nativo. El sustrato histórico de la mitología del ritual de los mayas, México: Fondo de Cultura Económica.

Ricoeur, P. (2006). Tiempo y narración. El tiempo narrado, volumen III, México: Siglo XXI.

Sánchez Vázquez, A. (2005). Invitación a la estética, México: Grijalbo.

Siemens, W. (1997). Mundos que renacen. El héroe en la novela hispanoamericana, México: Fondo de Cultura Económica.

Villoro, L. (1996). Creer, saber y conocer, México: Editores Siglo $\mathrm{XXI}$.

Viqueira, J. P.(1996). María de la Candelaria, india natural de Cancuc. México: Fondo de Cultura Económica.

(1997). Indios rebeldes e idólatras, dos ensayos históricos sobre la rebelión india de Cancuc, Chiapas, acaecida en el año de 1712, México: Ciesas.

(2002) "Las causas de una rebelión india: Chiapas, 1712", en Chiapas. Los rumbos de otra historia, (pp. 103-143), México: UNAM

(2010). "Resistencias indias a la rebelión tzeltal de 1712", en Anuario 2009, (pp. 213, 253), México: Unicach.

Ximénez, F. (1997). Historia de la provincia de San Vicente de Chiapa y Guatemala, Chiapas: Coneculta. 